\title{
Sistema de Turismo - SISTUR Estudo do Turismo face à Moderna Teoria de Sistemas
}

\author{
Mário Carlos Beni *
}

RESUMO: O tema, objeto deste trabalho, surge da necessidade de se dispor hoje, para o estudo rigoroso, met dico e científico do turismo, de um instrumento de trabalho ágil, dinânico, abrangente, moderno, simultaneamente setorizado e globalizante.

Para encontrá-lo ha que se analisar e identificar os múltiplos componentes do fato e do fenômeno do turismo, em suas inter-relaçôes de causa e efeito. Depois, definir e delimitar o campo de estudo do turismo segundo a Teoria dos Sistemas, relacionar sistemas antecedentes, interferentes e controlantes que constituem o ambiente do Sistema de Turismo - SISTUR, e conceituar, estruturar e operacionalizar as variáveis do Sistema para a construçāo de modelo referencial das relaçöes entre funçöes e operadores do SISTUR. Os resultados da utilização do SISTUR são de aplicação e interpretação as mais ricas possiveis, já que derivam dos sub-sistemas envolvidos no contexto configurante da atividade do turismo. Permitem, ainda, interferir na gestāo e controle dos agentes do turismo para reajustá-lo em decorrência de conjunturas e políticas de expansão, retração ou estagnação da atividade.

UNITERMOS: SISTUR - Sistema de turismo; turismo: teoria de sistemas, teoria; CADTUR - Cadastro de turismo (programa computacional para pesquisa da oferta e demanda por turismo).

ABSTRACT: This work emerges from a dual need of offering base model for tourim researchers, and an orderly, coherent and uniform tool of analitical concepts and procedures for students.

What is basically sought is the identification of the primary furctions of tourism, the operatives of the existing system and the matrixes of relations between the system as a whole and its subsystemic systerns.

The initial consolidation of the variables that interplay in the existence of the touristical fact was allowed through the creation of the Tourism System (Sistema de Turismo - SISTUR), through which unique perspectives are opened in the area.

KEY WORDS: SISTUR - Tourism system; tourism: systems theory, theory; CADTUR - Cadastre of tourism (computer program for supply and demand for tourism research).

(*) Professor Doutor do Curso de Turismo da ECA/USP. Membro do Conselho Consultivo da OMT - Organizaçāo Mundial de Turismo.

Membro do Conselho Diretor e Delegado do Brasil da AMFORT - Associaçāo

Internacional de Experts Cienkficos em Turismo.

Rua Bela Cintra, 2060 - 01415 - São Paulo - SP - Brasil. 


\section{INTRODUÇĀO}

O turismo é uma atividade que resulta do somatório de recursos naturais do meio ambiente, culturais, sociais e económicos e, assim, o campo de seu estudo é abrangente, complexo e multicausal. Para organizar esse imenso complexo de fatores - que sảo causas e efeitos intervenientes, năo se podendo afirmar, com certeza, ante mera especulação simplista, que fatores decidem a atividade turística e que fatores nåo a determinam -, é preciso dispor de um quadro referencial dinâmico, flexível, adaptável, de fácil leitura e compreensão, que integre toda essa colossal complexidade e a represente por inteiro em suas combinações. Tal instrumento e a Teoria de Sistemas.

A partir da Teoria de Sistemas, pode-se desenvolver um estudo circunstanciado sobre o turismo, no sentido de identificar os seus elementos com os respectivos atributos e as relações de causa e efeito, a fim de se delinear, com clareza, a extensão abrangida pelo Sistema de Turismo - SISTUR. Mas faz-se necessário, ainda, explorar outros sistemas para delimitar o campo de atuação do SISTUR.

O que se procura apresentar aqui é uma real consolidação, ordenada e estruturada, dos componentes do turismo, pois o que se nota é que os especialistas do assunto estudam um ou mais componentes em separado, tratando-os minuciosamente, mas não se preocupando, quase sempre, em correlacioná-los com os demais, também muito importantes, deixando de mostrar o quadro amplo e total em que surgem, tocam-se, entrelaçam-se e casam-se para produzir o fenómeno global.

Este trabalho leva, portanto, ao desenvolvimento da teoria e, ao se analisar os elementos que con̂̉stituem as relações do sistema com todos os componentes que a ele estão ligados, em interdependência, estrutura-se o Modelo Referencial do SISTUR.

Esses elementos, em suas linhas descritivas gerais, são:

1) delimitação e descrição física da área receptora, abrangendo o levantamento de:

a) recursos naturais e culturais;

b) equipamentos receptivos: de alojamento, hoteleiro, extra-hoteleiro e complementares de alimentação e recreação;

c) infra-estrutura de apoio à atividade turístico-recreativa.

2) perfil sócio-económico da área receptora, compreendendo o levantamento de

a) ocupação do território e densidade demográfica;

b) composição étnica da população e organização social; c) indicadores macro-econômicos, tais como: renda, investimentos de capital, consumo, importação e exportação;

d) indicadores dos setores da atividade económica, com ênfase no setor terciário.

3) Estudo da ordenaçāo geopolítica e administrativa da área receptora, compreendendo a necessidade do levantamento de:

a) organização institucional e legal;

b) grau de intervenção do Estado;

c) políticas básicas.

4) Estudo e previsōes do comportamento do mercado de turismo na área receptora, compreendendo o levantamento de:

a) oferta: indicadores de ocupação dos equipamentos receptivos e medidas de ocupação dos espaços de recreação;

b) demanda: quantificação e qualificação do ráfego turístico para caracterização e classificação dos fluxos em função de permanência, solicitaçōes de equipamentos e ouxas variáveis de consumo e mediủas de intensidade de participação nas várias a vidades ce recreação e entretenimento.

5) Diagnóstico có turismo na frra receptora, analisando-se seu potencial de influência no processo de desenvolvimento econômico. Para tanto, conhecidos em profundidade os elementos constitutivos das relaçōes do sistema, pode-se partir para a elaboração do prognóstico da situação da área receptora, que necessariamente exigirá eventuais ajustes para atingir o equilibrio do mercado.

Este será alcançado otimizando-se as áreas vocacionadas para o processo de ocupação turístico-recreaciva, aumentando o volume de novos investimentos, o nível de empregos e a quantidade de equipamentos, instalaçōes e serviços oferecidos.

\section{SISTEMA}

Na década de 1950, estudiosos introduzem idéias de sistemas, que exercem impacto ponderável, afetando todos os campos do conhecimento humano. Daí as referências nas mais variadas áreas do con̉hecimento à "abordagem sistêmica" ou "enfoque de sistemas".

\subsection{Definições}

Etimologicamente. Sistema $<$ Systema (grego) $<$ Synhistanai combinar $<$ syn + histanai $($ com + ser causa de ficar $=$ ser causa 
de ficar com), podendo-se definir sistema como um conjunto de partes que se interagem de modo a atingir um determinado fim, de acordo com um plano ou princípio; ou conjunto de procedimentos, doutrinas, idéias ou princípios, logicamente ordenados e coesos com intenção de descrever, explicar ou dirigir o funcionamento de um todo.

Bancal' oferece três definiçôes básicas de sistema:

a) definiçâo etimológica: conjunto de elementos associados em uma organização coerente, com o objetivo de construir um todo;

b) definiçāo descritiva: conjunto organizado e estruturado de elementos materiais ou imateriais, que constituem um todo ordenado e orientado;

c) definição pragmática: conjunto de práticas, de métodos e de instituiçōes que compõem, ao mesmo tempo, uma construção teórica e um método prático.

Hall e Fagen ${ }^{2}$ propōem, ainda, que sistema seja definido como "o conjunto dos elementos e das relaçōes entre eles e entre os seus atributos".

Por sua vez, Thornes e Brunsden ${ }^{3}$ enunciam sistema como "conjunto de objetos ou atributos e das suas relaçōes, que se encontram organizados para executar uma função particular' Nesta perspectiva, o sistema é um operador que, em determinado intervalo de tempo, recebe o input e o transforma em output.

Miller $^{4}$ apresenta outra definição, destacando que "sistema é um conjunto de unidades com relaçōes entre si". A palavra "conjunto" implica que as unidades possuem propriedades comuns. $O$ estado de cada unidade é controlado, condicionado ou dependente do estado das outras unidades. Assim, o conjunto encontra-se organizado em virtude das inter-relaçōes entre as unidades, e seu grau de organização permite que assuma a função de um todo que é maior que a soma de suas partes.

Em todas essas definiçōes, cumpre assinalar que os sistemas devem ter:

a) meio ambiente: conjunto de todos os objetos que não fazem parte do sistema em questão, mas que exercem algumas influências sobre a operação do mesmo;

b) elementos ou unidades: as partes componentes de um sistema;

c) relaçōes: os elementos integrantes do sistema encontram-se inter-relacionados, um dependendo dos outros, através de ligaçōes que denunciam os fluxos;

d) atributos: são as qualidades que se atribuem aos elementos ou ao sistema, a fim de caracterizá-los;

e) entrada ("input"): constituída por aquilo que o sistema recebe.
Cada sistema é alimentado por determinados tipos de entradas;

f) saída ("output" "): produto final dos processos de transformação a que se submete o conteúdo da entrada;

g) realimentaçâo ("feedback") : processo de controle que tem por finalidade manter o sistema em equilibrio;

h) modelo: é a representação do sistema. Constitui-se numa abstração para facilitar o projeto e/ou análise do sistema. É utilizado por dois motivos básicos: porque simplifica o estudo do sistema, permitindo a análise de causa e efeito entre os seus elementos para conclusōes de maior precisão; e pela impossibilidade de abranger a complexa totalidade das características e aspectos da realidade objeto de estudo.

$\mathrm{O}$ modelo tem sua construção baseada em informaçōes obtidas da realidade através da observação e/ou da medição. É, dessa forma, o instrumento mais útil, no presente estágio do conhecimento, para o estudo de sistemas. Acredita-se que uma ciência será tanto mais exata quanto maior for a correspondência entre os modelos que usa e a realidade.

\subsection{Considerações básicas}

Segundo Churchman ${ }^{5}$, cinco consideraçōes básicas devem ser sempre levadas em conta ao se ter em mente o significado de um sistema: " $l$. Os objetivos totais do sistema e, mais especificamente, as medidas de rendimento do sistema inteiro; 2. o ambiente do sistema: as coaçôes fixas; 3 . os recursos do sistema; 4. os componentes do sistema, suas atividades, finalidades e medidas de rendimento; 5. a auministraçâo do sistema"'

Os objetivos do sistema global são o ponto lógico para começar porque muitos erros podem ser cometidos no pensamento subseqüente a respeito do sistema, se forem ignorados os verdadeiros objetivos da totalidade. Preliminarmente, porém, deve-se ter consciência de uma confusão relativa à palavra "objetivo". Os habitantes de sistemas gostam de enunciar seu objetivo, e os enunciados que proferem têm um certo número de finalidades que são de todo independentes do rendimento do sistema.

Com o fim de tornar claro o assunto, o cientista precisa passar do vago enunciado de objetivos para algumas medidas precisas e especificas de rendimento do sistema global. A medida do rendimento de um sistema é uma contagem de pontos, por assim dizer, que diz até onde o sistema está funcionando bem. Quanto maior o número de pontos, melhor o rendimento. Um estudante, na aula, muitas vezes chega a pensar que seu objetivo é alcançar a nota mais alta possível. Neste caso a medida do rendimento torna-se inteiramente clara, e é 
interessante para muitos professores observar que os estudantes procuram alcançar uma nota alta mesmo com o sacrifício da compreensão real do conteúdo do curso. Procuram a nota alta porque acreditam que as notas altas levarão a obtenção de bolsas e outras oportunidades no futuro. Sua finalidade declarada é aprender, mas sua medida real do rendimento é a nota. Da mesma maneira, se se observar cuidadosamente certas cidades, pode-se chegar a esperar que o objetivo real do governo da cidade é manter as oportunidades dos cidadãos de alto rendimento, proporcionando-lhes áreas satisfatórias para viver e recursos e espaços satisfatórios para seu trabalho. Assim, as pretensões de que a cidade se esforce por servir a todos os cidadãos são refutadas pelo desejo do prefeito da cidade de sacrificá-las em favor de garantir as oportunidades das categorias de alto rendimento. A medida real do rendimento é a aptidão da cidade em conservar grandes indústrias nos limites urbanos e mànter o nível de rendimento do grupo de alto rendimento tão elevado quanto possível.

No setor de Turismo, pode-se imaginar a priori que tanto a área estatal quanto a empresarial têm como objetivo real o lucro. O Estado espera do setor o superávit no balanço de pagamentos, na conta específica, em razão de ingressos de divisas, e as empresas que atuam no setor igualmente dimensionam a prestação de seus serviços em razão da lucratividade dos investimentos necessários. Entretanto, ao se analisar as partes do sistema, vai-se verificar que a medida de seu rendimento global está na razão direta da capacidade de controle de seus componentes e atividades, e nem sempre esse rendimento está vinculado ao lucro. Ao Estado compete o investimento social não somente na infra-estrutura de apoio à atividade, como na implantação de programas de turismo socializado com o objetivo de facilitar o acesso ao turismo às classes menos favorecidas economicamente. E esse estrato da demanda somente poderá ser atendido e viabilizado sem objetivo de lucro e recuperação dos investimentos. A empresa privada igualmente terá que investir na qualificação de mảo-de-obra e aperfeiçoamento de pessoal, sacrificando parte de seu lucro líquido.

Assim, na determinação de uma medida de rendimento, o cientista procurará encontrar o máximo de conseqüências importantes das atividades do sistema. Reconhecidamente, ele também cometerá enganos e terá de rever sua opinião à luz de novos conhecimentos. Mas sua insistência e atenção, e a intenção de ser tão objetivo quanto possivel lhe permitirảo reduzir ao mínimo os erros

$O$ aspecto seguinte do sistema que o cientista deve considerar é o seu ambiente $\mathrm{O}$ ambiente do sistema é aquilo que está situado 20 "fora" do sistema. Isto também não é uma coisa fácil de definir. Ao se considerar um hotel, pode-se fazer uma primeira tentativa analisando e elencando tudo o que está em seu interior e o que está fora dele. Poder-se-ia, então, arriscar a afirmação de que tudo quanto se acha além das paredes do hotel ou de seu entorno está no ambiente do hotel. O hotel pode pertencer a uma cadeia de hotéis e ser uma unidade desse conglomerado; pode ter, e certamente terá, representantes em várias partes do paŕs para vender seus serviços e instalações, e, neste caso, estes são seguramente "parte' do sistema total do hotel e, contudo, não estão habitualmente dentro de seus limites.

Por conseguinte, o cientista deve ter uma maneira de pensar a respeito do ambiente do sistema que seja mais rica e mais sutil do que a simples procura de limites. Quando se diz que alguma coisa está situada "fora" do sistema, isto significa, na realidade, que o sistema pode fazer relativamente pouco a respeito das características ou comportamento de tal coisa. O ambiente, com efeito, constitui-se das coisas e pessoas que são "fixadas" ou "dadas" do ponto de vista do sistema. Por exemplo, se um sistema opera dentro de um orçamento fixo que lhe é dado por algum órgão superior e o orçamento não pode ser alterado por qualquer atividade do sistema, ter-se-ia de dizer então que as restrições orçamentárias encontram-se no ambiente do sistema. Mas se, por alguma transformação da organização, o sistema puder influir no orçamento, então alguns dos processos orçamentários pertenceriam ao interior do sistema.

Não apenas o ambiente é alguma coisa que está fora do controle dos sistemas mas é também algo que deternnina, em parte, o funcionamento do sistema.

\section{TURISMO}

Há tantas definições de turismo quanto autores que tratam do assunto. Mas quanto maior o número de pesquisadores que se preocupam em estudá-lo, tanto mais evidente se apresentará a amplitude e a extensão do fenômeno do turismo e tanto mais insuficientes e imprecisas serão as definiçōes existentes. Muitos autores chegam a considerar a extrema dificuldade para uma definição precisa e abrangente de turismo, levando em conta que o fenômeno é tão grande e complexo que se torna praticamente impossível expressá-lo corretamente e, por isso, preferem observar invariavelmente seus aspectos parciais ou, pelo menos, algumas de suas realidades isoladas.

3.1 Conceitos

As mais diversas noções de turismo apresentam alguns elementos comuns ou relativamente diferentes entre elas, que convém destacar para melhor compreensão do fenômeno, e que são: 


\subsubsection{Viagem ou Deslocamento}

Este $e ́$ um elemento implícito na noção de turismo. O movimento está intimamente conectado ao próprio sentido etimológico do termo - TOUR - viagem em circuito - deslocamento de ida e volta. Sem o deslocamento não existe turismo e, ainda que pareça o óbvio, para se aprofundar na correta noção do fato e do fenômeno do turismo, $\epsilon$ necessário colocar em destaque este seu elemento indispensável.

\subsubsection{Permanência Fora do Domicilio}

Estreitamente vinculado à viagem, o elemento de permanência fora da própria residência habitual $\varepsilon$ parte integrante do conceito de turismo. A duração dessa permanência é uma das variáveis principais na caracterização e classificação do fluxo. Também o é a solicitação do equipamento receptivo na destinação da viagem. Esta variável combinada com a anterior, a permanência, e somada à de comportamento de gastos do turista no local, constituem, no cruzamento com outras variáveis auxiliares, a base da compreensão estrutural do tráfego turístico.

\subsubsection{Temporalidade}

A viagem e a permanência são os dois primeiros elementos característicos, mas resultam insuficientes para configurar o fenômeno. Viajantes podem ser tambem aqueles que se transferem a uma outra localidade de seu país ou de uma outra nação para fixar residência estável ou definitiva. Neste caso é certo que não se trata de turista mas de um emigrante.

\subsubsection{Sujeito do Turismo}

Elemento subjetivo caracterizante de todo o fato e fenômeno do turismo $\varepsilon$ o homem. Sobre isso não pode haver nenhuma dúvida. $\mathrm{O}$ homem se situa no centro de todos os processos que nascem do turismo. Como afirma o Prof. Hunziker ${ }^{6}$, "o homem é o verdadeirø centro do turismo"; dar se depreende que a função econômica do tưrismo é subsidiária enquanto "a sua missão humanitária é eminer:te". O homem, com seu desejo e sua necessidade, dá origem às várias atividades econômicas causadas pelo turismo; esta $\epsilon$ a primeira $\mathrm{e}$ 22 direta derivação. O turista é também a fonte de uma série de elementos não materiais que surgem da sua permanência na localidade turística e que se completam em uma série de relações humanas e materiais, de cuja complexidade e beleza o fenômeno se reveste.

\subsubsection{Objeto do Twismo}

O elemento objetivo do fenômeno traduz-se pelo equipamento receptivo e fornecimento dos serviços para a satisfação das necessidades do turista, a que se denomina de Empresa Turística. Esta empresa é complexa e, em grande parte, responsável pela produção, preparação e distribuição dos bens e serviços turísticos. Pode-se conceituar bem turístico como todos os elementos subjetivos e objetivos ao nosso dispor, que são dotados de apropriabilidade, passíveis de terem atribuído um valor econômico, ou seja, um preço.

Quanto aos bens subjetivos ou imateriais, não apropriáveis, de difícil valorização, como ar puro, o mar, as belezas naturais, $\epsilon$ indubitável que estão hoje adquirindo, como nunca, altos valores econômicos devido aos conglomerados urbanos sempre crescentes e às dificuldades de fruição, por todos, de um estilo de vida natural. Sua apropriabilidade traduz-se pela sua capacidade de utilização coletiva.

Os bens turísticos podem ser:

a) materiais (monumentos, museus, galerias de arte, praias e outros) e imateriais (clima, paisagem e outros);

b) imóveis (terrenos, casas, hotéis, museus, galerias e outros) e móveis (produtos artísticos, artesanatos e culturais);

c) duráveis ou perecíveis (produtos gastronômicos e artesanais);

d) de consumo (bens que satisfazem diretamente as necessidades dos turistas) e de capital (os que são utilizados para a produção de outros bens);

e) básicos, complementares e interdependentes;

f) naturais ou artificiais.

Os serviços turísticos, destinados à satisfação das motivações, necessidades e preferências do turista, podem ser classificados como os seguintes:

a) receptivos (atividades hoteleiras e extra-hoteleiras);

b) de alimentação;

c) de transporte (da residência à destinação turística e no centro receptor);

d) públicos (administração turística, postos de informações e outros);

e) de recreação e entretenimento na área receptora. 


\subsection{Linhas de Análise Teórica}

Para melhor visāo do fato e do fenômeno do turismo. distinguem-se três linhas diferentes de análise teórica da atividade turística:

a) a primeira se coloca na perspectiva de produçāo e envolve uma pluralidade de empresas que atuam no setor, algumas das quais operam a transformaçāo de matéria-prima em produto acabado, enquanto outras oferecem bens e serviços já existentes;

b) a segunda linha conceitual refere-se à distribuiçāo do produto ao consumidor. Aqui há uma visível analogia entre a atividade de produçāo com a de distribuiçāo, pois sendo um setor no qual se produzem preferencialmente serviços, é também um setor de atividade no qual o momento produtivo pode corresponder ao distributivo, com a passagem dos bens e serviços turísticos diretamente do produtor ao consumidor;

c) a terceira linha de raciocínio consiste em identificar e estabelecer as condicionantes da viagem e os componentes comportamentais do viajante, isto é, a origem da viagem, os meios de transporte utilizados, a natureza da viagem, o tempo de permanência no local, os equipamentos receptivos solicitados, suas motivaçōes, necessidades e preferências, o grau de participação nas atividades turístico-recreativas de sua destinaçāo - a estrutura de gastos -, e a estratificação sócio-econômica do consumidor.

Resumindo, para efeito de melhor compreensāo das três linhas indicadas, pode-se dizer que a primeira procura saber quais os segmentos produtivos e empresas que devem denominar-se especificamente turísticas, o conjunto das quais indica o setor turismo na economia; a segunda procura definir as relaçōes do turismo com o resto da atividade económica para o que se serve das definiçōes de turismo provenientes da primeira, que considera a atividade a partir do lado da oferta e a última que o faz a partir da demanda; a terceira gira em torno da própria definiçāo do turista, cujas atividades, por extensāo, permitem determinar o que se entende por turismo.

\section{SISTEMA DE TURISMO - SISTUR}

Ao se conceituar sistema como o conjunto de procedimentos, doutrinas, idéias ou princípios logicamente ordenados e coesos, com intençāo de descrever, explicar ou dirigir o funcionamento de um todo, teve-se em mente situar o turismo. em toda a sua abrangência, complexidade e multicausalidade. em um esquema sintetizador dinâmico que demonstre as combinaçōes multifacetadas de forças e energias, sempre em movimento, de modo a produzir um modelo re ferencial Este tem de ser capaz de retratar, até os seus limites máximos, a configuraçāo que tenta assumir um fato e um fenômeno como o do turismo, tāo sujeito a variáveis internas e externas que escapam, no momento de análise científica, a praticamente quase todo esforço de cristalizaçāo para se poder estudá-las, determiná-las e avaliá-las.

Para tanto, relacionou-se uma série de funçōes inerentes à natureza da atividade de turismo, tais como: o conjunto de fatores que geram as motivaçōes de viagens e a escolha das áreas de destinaçāo turística; deslocamento de indivíduos no contínuo espaço-tempo; os equipamentos de transporte oferecidos ao tráfego de pessoas; o tempo de permanência na área receptora; a disponibilidade e a solicitação não só de equipamentos de alojamento hoteleiro e extra-hoteleiro, bem como os equipamentos complementares de alimentação; a disponibilidade e a solicitaçāo de equipamentos e instalaçōes de recreação e entretenimento; a fruição dos bens de intermediação de serviços; e a estrutura e o comportamento de gastos. Emergem desse repertório de funçōes primárias e inerentes à ativiđade funçōes derivadas, que ampliam e consolidam o contexto em que aquela se processa, contidas no ambiente natural, cultural, social e econômico, e nas funçōes de organizaçāo e operacionalizaçāo. A partir dessa base conceitual pode-se configurar o diagrama de contexto do Sistema de Turismo, que permite visualizar três grandes conjuntos: relaçōes ambientais, organizaçāo estrutural e açōes operacionais, bem como seus componentes básicos e as funçōes primárias atuantes em cada um dos conjuntos e em interaçāo no sistema tota! (Figura 1).

Cada componente desses três conjuntos pode ser considerado um sub-sistema em si, já que apresenta funçōes próprias e específicas, assumindo características individualizadas. Essas funçōes, quando organizadas para explicar e justificar o fato e o fenômeno do turismo, já delineiam o arcabouço do sistema, com objetivos em si.

No momento em que se correlaciona a atividade do turismo em si, por exemplo, a uma atividade econômica isolada do setor de serviços, como transportes, esta passa a integrar o sistema de turismo, com um objetivo próprio. Para ilustrar isto, considere-se uma empresa aérea que ransporta carga e 'ou passageiros de uma localidade a outra, que é um objetivo em si. Se se consiçerar c fuxo de passageiros entre essas localidaces. evandc em conta variáveis como motivaçāo, gastos, promoçāo c outras, estar-se-á atribuindo a uma função puramente economica, exógena, a qualidade turística, portanto endógena e integrante do sistema. 




26
Na mesma linha de raciocínı. poder-se-ia imaginar o complexo hidrelétrico de Paulo Afonso, cuja tunção específica é gerar energia, mas que tem. em seu cenário, força de atração turística, constituindo-se. portanto. num espaço de fruição paisagística, participante do sistema. Adotando esse procedimento para com todas as outras funçōes, chega-se logicamente à integração articulada dos conjuntos que acionam o funcionamento do Sistema Global.
4.1 Objetivos
$w \times \circ$

4.1.1 Geral

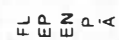

Organizar o plano de estudos da atividade de turismo, levando em consideração a necessidade, há muito tempo verificada nas obras tebricas e pesquisas publicadas nos países a que se tem acesso, de fundamentar as hipóteses de trabalho, justificar posturas e princípios cient'́ficos, aperfeiçoar e padronizar conceitos e definiçōes, e consolidar condutas de investigação para instrumentar análises e ampliar a pesquisa, com a conseqüente descoberta e desenvolvimento de novas áreas de conhecimento do setor.

\section{Espectficos}

Podem ser citados os seguintes:

a) identificar características e classificar os fatores que determinam as motivaçōes de viagens e a escolha das áreas de destinação turístico-recreativa.

b) inventariar de forma estruturada e sistêmica, o potencial de re cursos turísticos naturais do território para a exploração racional da atividade de turismo e recreaçăo:

c) dimensionar a oferta existente e/ou projetada de transportes e equiparnentos, instalaçōes e serviços para o processo de ocupação turístico-recreativa do território;

d) quantificar e determinar a demanda existente e/ou projetada de bens e serviços turísticos;

e) diagnosticar deficiências, pontos críticos e de estrangulamento, desajustes entre a oferta e a demanda existentes;

f) permitir a previsão do comportamento do mercado através de análise de tendências: 
g) formular diretrizes de reorientação de programas de ação para de terminar o planejamento estratégico do desenvolvimento do setor

h) planificar e executar o desenvolvimento do produto turístico, mediante preparação de um plano integral de "marketing",

i) avaliar e executar campanhas de promoção do produto turístico;

j) analisar o significado econômico do turismo e seu efeito multiplicador no desenvolvimento nacional;

k) organizar a atividade de turismo na estrutura administrativa do setor público;

1) idealizar a estrutura otimizada do organismo nacional de turismo;

m) indicar procedimentos de execução e controle de gestão setorial e global e políticas ágeis em seus subconjuntos;

D) criar modelos formais e matemáticos das marizes de relaçōes das funçöes e operadores.

\subsection{Ambiente}

A conceituação do que venha a ser o ambiente do Sistema é uma questão complexa, que foge a todo esforço no sentido do delimitá-lo Requer-se, por isso mesmo, que sua apresentação conceitual seja bem mais sutil do que a mera busca de limites. Cumpre lembrar que, quando se diz que alguma coisa está situada "fora" do Sistema, quer-se significar que o Sistema pode fazer relativamente pouco a respeito das características ou do comportamento de tal coisa. Por exemplo, o sub-sistema econômico, visto sob a ótica do turismo, untegra o SISTUR, mas isso não quer dizer que este vá determinar o Sistema Economico. na realidade, significativamente mais amplo, do qual o turismo é apenas um segmento.

Não apenas o ambiente é alguma coisa que está fora do controle do Sistema, mas é também algo que determina em parte o funcionamento do Sistema.

Na concepçâo do SISTUR, pode-se depreender claramente que os sub-sistemas Ecológico, Econômico, Social e Cultural foram agrupados no Conjunto das Relaçōes Ambientais, pois, enquanto sistemas isolados na sua concepção maior estão "fora" do Sistema ao mesmo tempo em que, como sistemas antecedentes e controlantes, com açōes específicas que influenciam decisivamente a atividade de turismo, acham-se dentro do Sistema. O mesmo se verifica com to dos os demais Conjuntos de Sub-sistemas

\subsection{Recursos}

()s recursos são o reservatório geral, a partir do qual as açōes especificas do sistema podem ser formadas, isto é, encontram-se dentro do sistema, sendo os meios que utiliza para desempenhar suas tarefas.

As açōes específicas são recebidas pelos conjuntos de sub-sis temas, atuando em interação com seus componentes. Nesse sentido, as açōes do Conjunto das Relaçōes Ambientais do Sistema que envolvem sub-sistemas distintos e autônomos à primeira vista, tais como, por exemplo, o Ecológico e o Econômico, ao serem evocadas para justificar e determinar funçōes da atividade de turismo, convertem-se em açōes específicas do Sistema.

Para ilustrar uma ação específica econômica no turismo tem-se a taxa de cobertura das importaçōes. As açōes específicas são identificadas a partir do tratamento sistêmico das resultantes dos operadores e constituem o elenco de "inputs" que, processados, podem gerar resultados diretos satisfatórios ou não. Neste último caso, há que se proceder a ajustes para a retroalimentação.

\subsection{Componentes}

Os componentes do Sistema nada mais são do que os sub-sistemas identificados nos Conjuntos das Relaçōes Ambientais, da Organização Estrutural, e das Açōes Operacionais do SISTUR, quais sejam, os sub-sistemas Ecológico, Econômico, Social, Cultural, da Superestrutura, da Infra-Estrutura, do Mercado, da Oferta, da Demanda, de Produção, de Distribuição e de Consumo (Figura 2).

\section{Conjunto das Relaçôes Ambientais}

\subsubsection{Sub-sistema Ecológico}

Tem como principal elemento a contemplação e o contato com a natureza, matéria-prima do turismo Analisam-se, nesse sub-sistema, os seguintes fatores, com suas respectivas funçōes, variáveis e regras de consistência:

a) espaço turístico natural e urbano, e sua planificação territorial;

b) atrativos turísticos.

c) conseqüências do turismo sobre o meio ambiente, preservação da flora, fauna e paisagens 


\subsubsection{Sub-sistema Social}

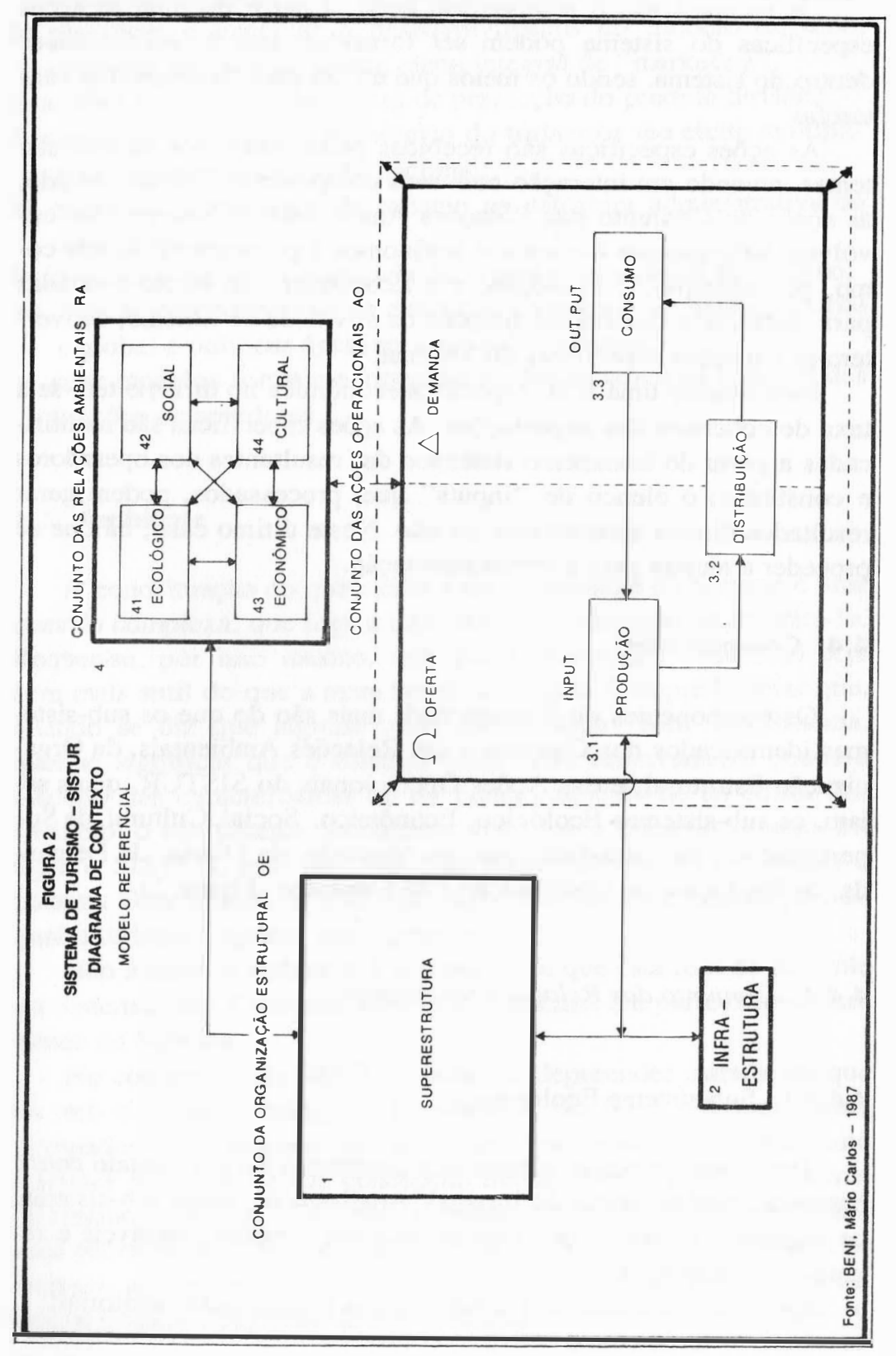

30
Tem como principal elemento a estrutura e mobilidade social e seus efeitos. Analisam-se, nesse sub-sistema, os seguintes fatores, com suas respectivas funçð̄es, variáveis e regras de consistência:

a) populaçāo autóctone no processo de contato social nas áreas de ocupaçāo turística;

b) perfil psico-sociologico do turista;

c) motivaçōes, expectativas e necessidades do turista; $e$

d) estratifícaçāo social dos grupos de turistas.

\subsubsection{Sub-sistema Econômico}

Tem como principal elemento a contribuiçāo econômica para o desenvolvimento nacional. Analisam-se, nesse sub-sistema, os seguintes fatores, com suas respectivas funçōes, variáveis e regras de consistência:

a) ingresso de divisas;

b) receita nacional e geraçāo de empregos;

c) formaçāo do Produto Interno Bruto; e

d) efeito multiplicador da economia.

\subsubsection{Sub-sistema Cultural}

Tem como principal elemento a herança e o património cultural do país. Analisam-se, nesse sub-sistema, os seguintes fatores, com suas respectivas funçōes, variáveis e regras de consistência:
a) património etnográfico;
b) legado histórico, arqueológico, arquitetônico e monumental;
c) património artístico, folclórico e artesanal;
d) usos e costumes diferenciados.

\subsubsection{Conjunto da Organizaçāo Estrutural}

\subsubsection{Sub-sistema da Superestrutura}

Tem como principal elemento o ordenamento jurídico-adminitrativo de gestāo e controle do SISTUR. Analisam-se, nesse sub-siste- 
ma, os seguintes fatores, com suas respectivas funçōes, variáveis e regras de consistência

a) planificação estratégıca do turismo.

b) indicadores macro-económicos. e

c) oumanizaçāo e fiscalização dos agentes operadores do turismo.

\subsubsection{Sub-sistema da Infra-Estrutura}

Tem com principal elemento o estudo das condições de acessibilidade à área de destinação turística e dos serviços. Analisam-se, nesse sub-sistema, os seguintes setores, com suas respectivas funções, variáveis e regras de consistência:

a) saneamento básico

b) energia e comunicaçōes;

c) serviços de apoio;

d) sistema viário e de transportes; e

e) organização territorial urbana.

\subsubsection{Conjunto das Açðes Operacionais}

Representa o sub-sistema do Mercado, compreendendo oferta e demanda, e os processos de produção, distribuição e consumo. Analisam-se, nesse sub-sistema, os seguintes setores, com suas respectivas funçōes, variáveıs e regras de consistência

a) áreas de captação dos consumidores ongem dos turistas):

b) localizaçã̃o, concentração. estrutura e características do tráfego turístico.

c) caracterızação, classificação e evolução dos fluxos turísticos;

d) expansão ou retração de fluxos;

e) variação estacionai da demanda:

f) oferta e ocupação de equipamento hoteleiro e extra-hoteleiro;

g) avaliação dos produtos turísticos;

h) avaliação e rentabilidade dos investimentos necessários à evolução da demanda e da renda nacional;

i) avaliação das unidades produtivas de bens e serviços turísticos;

j) circuitos distributivos e estratégias de distribuiçáo de bens e serviços turísticos:

k) processo de decisảo de compras; e

l) consumo turístico e efeitos sobre a renda nacional

Na realidade, o Sistema não precisana ser dividido em compooentes, a razão por que $\epsilon$ feita está em proporcionar, ao analista, c tipo de informação de que necessita para dizer se o Sistema está operando corretamente e o que deveria ser feito para aperfeiçoá-lo. No caso específico do Sistema de Turismo, a necessidade de dividilo em componentes é premente em virtude das inúmeras inter-relaçōes verificadas em cada um dos conjuntos de sub-sistemas que também interagem entre si no sistema total.

\subsection{Administração}

Por administração do SSistema entende-se a criação de planos que envolvem os objetivos globais, o ambiente, a utilização dos recursos e os componentes.

Atualmente entende-se por Administração do Sistema o processo de controle de seu rendimento, sendo que os procedimentos desse controle operam em caráter excepcional, por exemplo, nas operações de um componente, interferindo nele somente quando há um excessivo desvio de sua ação específica. Convém ressaltar que a administração do sistema não apenas engendra os planos doSistema, mas deve também assegurar que estes sejam executados de acordo com os objetivos originais; se não forem, a administração deve determinar por que não o são, reavaliando pelo processo de retroalimentação de intervenção, em qualquer parte do Sistema, para os ajustes ou mudanças que se fizerem necessários.

A Administração do Sistema é o único controle efetivo de que se dispõe para indicar as causas dos desajustes entre os Conjuntos de Sub-sistemas em relação ao Sistema Global, e determinar procedimentos de correção e de retorno ao equilíbrio, para otimizar as relaçōes entre funções e operadores. No caso do SISTUR, o processo de controle de 'seu rendimento é feito através do Sub-sistema da Superestrutura que, na realidade, constitui o instrumento de Administração do Sistema Global.

\section{CONSIDERAÇŌES FINAIS}

Verificou-se que a complexidade do fato e do fenômeno do turismo pode ser reduzida a um modelo referencial, que utiliza a noção de Sistema para retratar toda a riqueza e dinâmica das variáveis envolvidas, permitindo obter uma configuração ordenada de como se processam os movimentos e as inter-relaçōes das funçōes turísticas com os componentes do sistema construído - o SISTUR. Assim, com a identificação objetiva dos componentes do SISTUR e dos grandes 
conjuntos de sub-sistemas que o integram, o profissional de turismo dispōe de instrumentos próprios para aperfeiçoar a pesquisa. Por outro lado, a utilização do SISTUR propicia que a atenção seja localizada para o fato de o turismo não ser uma manifestação isolada, demonstrando que todas as áreas do meio ambiente natural e da vida social se interligam para produzi-lo através da vontade de seu agente. E também evidencia a necessidade de manter sempre em equilfbrio a oferta e a demanda turísticas, no regime de mercado livre e aberto, para a produção de sua contribuição à economia e ao desenvolvimento nacionais.

Como todo sistema, o SISTUR tem necessidade de intervençōes ágeis e especializadas, através de estratégias planificadas, para mantê-lo em estado de operação otimizado. Permite, ainda, o processo de pronta recuperação de dados e informaçōes necessário para vánias integraçōes, como a integração do turismo ao desenvolvimento nacional e com outros setores sócio-económicos, a integração das funçóes turísticas primárias, a integração das atividades e esforços do setor público e do setor privado, a integração dos diversos componentes da atividade turística, a integração do desenvolvimento do Turismo Internacional e Intercontinental com o Turismo Interno, a integração dos elementos e atrativos naturais com os criados e construfdos pelo homem, e a integração do património histórico-cultural com as expressōes sócio-culturais modernas e a utilização turística.

O SISTUR, enfim, instrumentaliza o estudioso, dando-lhe meios para utilizar matrizes de relações entre funçōes do turismo e operadores do sistema, convergentes para a adoçāo de modelos matemáticos que, além de serem inovadores, constituem-se em verdadeiros precursores de uma abordagem e de uma investigação rigorosamente cientfficas do turismo.

\section{REFERÊNCIAS BIBLIOGRÁFICAS}

1. BANCAL, J. L'économie des sociologues. Paris: PUF, 1974. p. 231

2. HALL, A.D. \& FAGEN, R.E. Definition of systems. General Systems Yearbook. n. 1, p. $18-26,1956$.

3. HALL, J.B. \& BRUNSDEN, D. Geomorphology on Time. London: Methuen, 1977, p. 209.

4. MILLER, J.G. Living systems: basic concepts. Behavioral Science, n. 10, p. 193-237, 1965.

5. CHURCHMAN, G.W. Introdução d teoria dos sistemas. São Paulo: Vozes, 1972.

6. HUNZIKER, W. Os palses em vias de desenvolvonento. Berna: AIEST, 1962. p.3.

7. BENI, M.C. Sistema de turiono: construçc̃o de um madelo teórico referencial para aphcaşāo na pesquisa em turiono. São Paulo: ECA/USP, 1988. 766 p. (Tese de Doutoramento) 